\title{
Updates to the on-land seismogenic structure source database by the Taiwan Earthquake Model (TEM) project for seismic hazard analysis of Taiwan
}

\author{
J. Bruce H. Shyu ${ }^{1, *}$, Yu-Hsuan Yin ${ }^{1}$, Cheng-Hung Chen ${ }^{1}$, Yi-Rung Chuang ${ }^{1,2}$, and Sze-Chieh Liu ${ }^{1}$ \\ ${ }^{I}$ Department of Geosciences, National Taiwan University, Taipei City, Taiwan \\ ${ }^{2}$ Disaster Prevention Technology Research Center, Sinotech Engineering Consultants, Inc., Taipei City, Taiwan
}

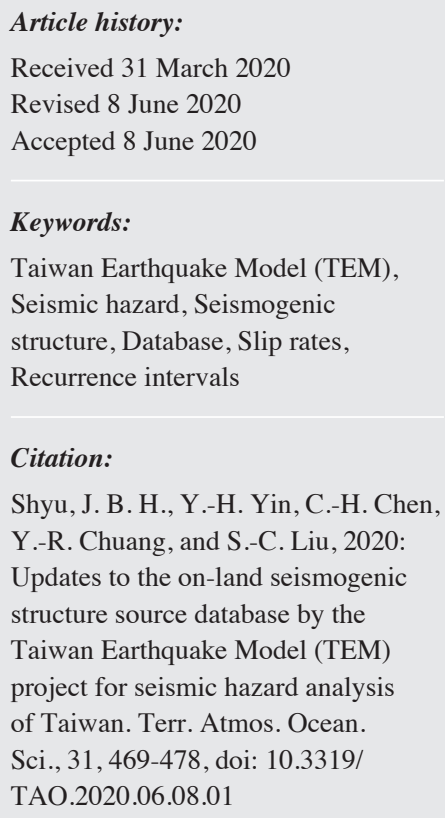

\begin{abstract}
To provide information towards understanding Taiwan's earthquake hazard and risk, the multi-disciplinary Taiwan Earthquake Model (TEM) project, supported by the Ministry of Sciences and Technology, had prepared and published a first version of seismic hazard assessment maps of Taiwan in 2016, together with an on-land seismogenic structure database of the island. In the years following the publication of this first version, we have constructed an updated version of this database. Seven structures were identified and added to the database. Based on additional information, we have also updated the structural parameters of four existing structures, as well as systematically updated the parameters of all structures to include more complete parameter uncertainties. This update of the database represents the most up-to-date information of seismogenic structures in Taiwan, and would provide better constraints for future seismic hazard assessment and mitigation studies.
\end{abstract}

\section{INTRODUCTION}

As a young mountain belt located at an active plate boundary, Taiwan is characterized by numerous active faults and seismic activities. For example, the $1999 \mathrm{M}_{\mathrm{w}} 7.6$ Chi-Chi earthquake that was produced by ruptures along the Chelungpu fault in central western Taiwan (e.g., Central Geological Survey 1999) was one of the most destructive natural disasters in Taiwan's written history. This disaster undoubtedly showed the urgent need for a better understanding of Taiwan's future earthquake hazards (e.g., Shyu et al. 2005; Cheng et al. 2007, 2010). Consequently, the multidisciplinary Taiwan Earthquake Model (TEM) project was carried out by a team of earthquake scientists in Taiwan to obtain detailed information for seismic hazard assessment and risk management for the island.

In 2016, as a result of such multi-disciplinary efforts,

\footnotetext{
* Corresponding author

E-mail:jbhs@ntu.edu.tw
}

the first version of seismic hazard assessment maps of Taiwan was published (Wang et al. 2016), together with a new on-land seismogenic structure source database with 38 structures in Taiwan (Shyu et al. 2016). Based on geological and geomorphological information, this database summarized and analyzed the locations, geometries, long-term slip rates, and earthquake recurrence intervals of those 38 structures. However, as pointed out by Shyu et al. (2016), this database is by no mean complete, and needs to be updated regularly as more data become available.

Therefore, this study provides the first update for the on-land seismogenic structure source database by the TEM project since the publication of its first version (Fig. 1 and Table 1). Results from several new and past publications were integrated into the database, together with new results from our own field investigations and calculations. The primary updates include three parts, and will be described in detail in the following sections: 
(1) We have added seven new structures (\#39 to \#45) into the updated on-land seismogenic structure database, based on results from several new and past publications. Structural parameters of these newly added structures were also evaluated and included in the updated database.

(2) On the basis of results from new publications and our own field investigations, we have updated the structural parameters of four seismogenic structures in the original database, including the Maoli frontal structure (\#10), the Houchiali fault (\#25), the Hengchun fault (\#30), and the Hengchun offshore structure (\#31).

(3) In order to consider additional uncertainties for the structural parameters, we have also used alternative calculation methods proposed in the literature. The systematically updated structural parameters for all structures are now included in the new database.

\section{NEW SEISMOGENIC STRUCTURES OF THE TEM DATABASE}

In this updated seismogenic structure database, we have identified and added seven new structures to the original database (Shyu et al. 2016). These new structures are numbered from 39 to 45 (red lines in Fig. 1). Among these seven structures, five of them (\#39, \#40, \#42, \#43, \#45) were previously proposed as active structures in published literatures. Therefore, we have mapped those structures and collected their structural geometric parameters based on the information in these literatures. The geometric parameters of the other two structures were obtained from our own mapping results.

As mentioned in Shyu et al. (2016), the constraints for the seismogenic structures' long-term slip rates are still very

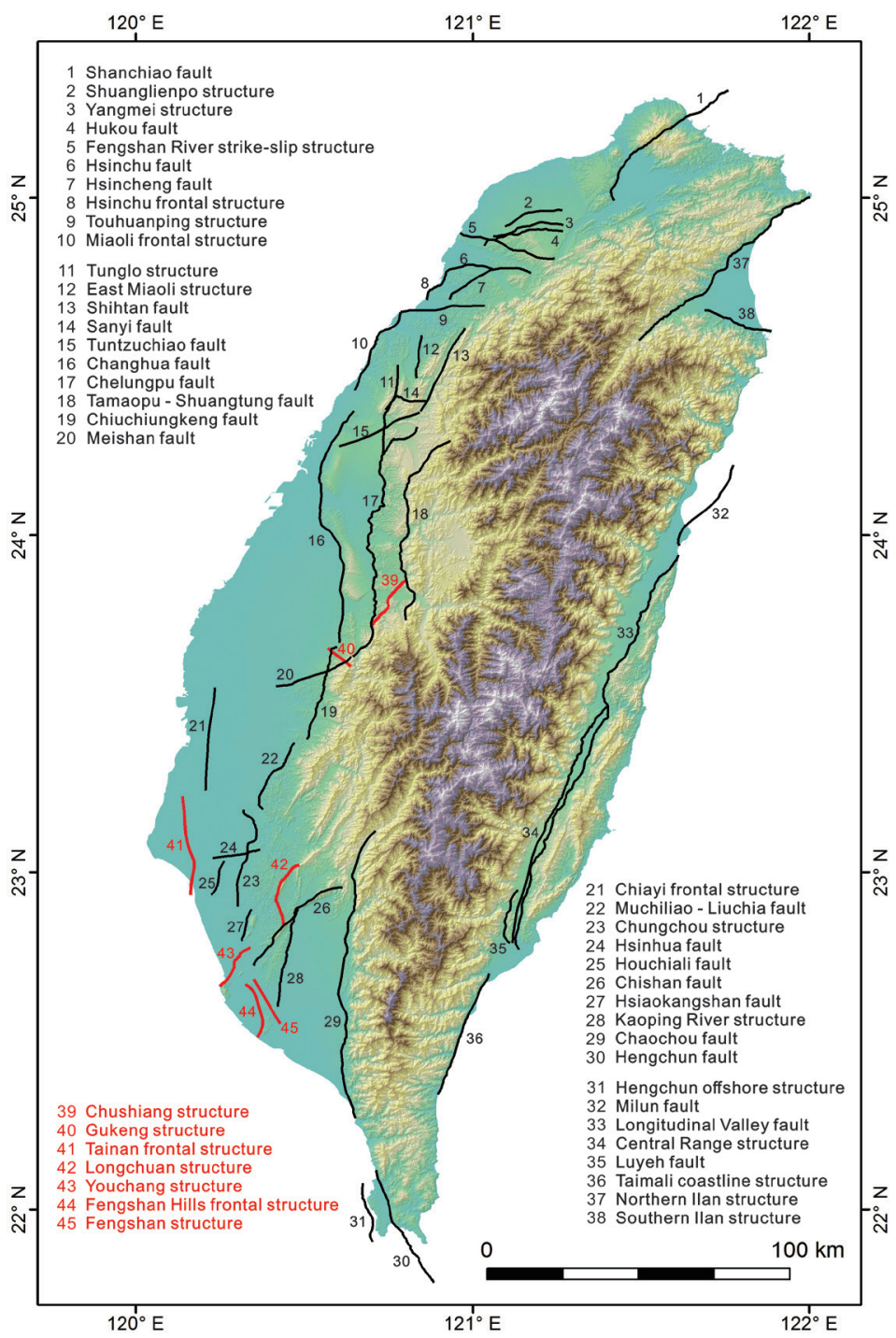

Fig. 1. Updated map of major on-land seismogenic structures of Taiwan. In total, 45 structures were identified in this new version of the database. The red lines show the newly added structures of the new version (\#39 to \#45). The black lines are the 38 structures in the original version (Shyu et al. 2016). 


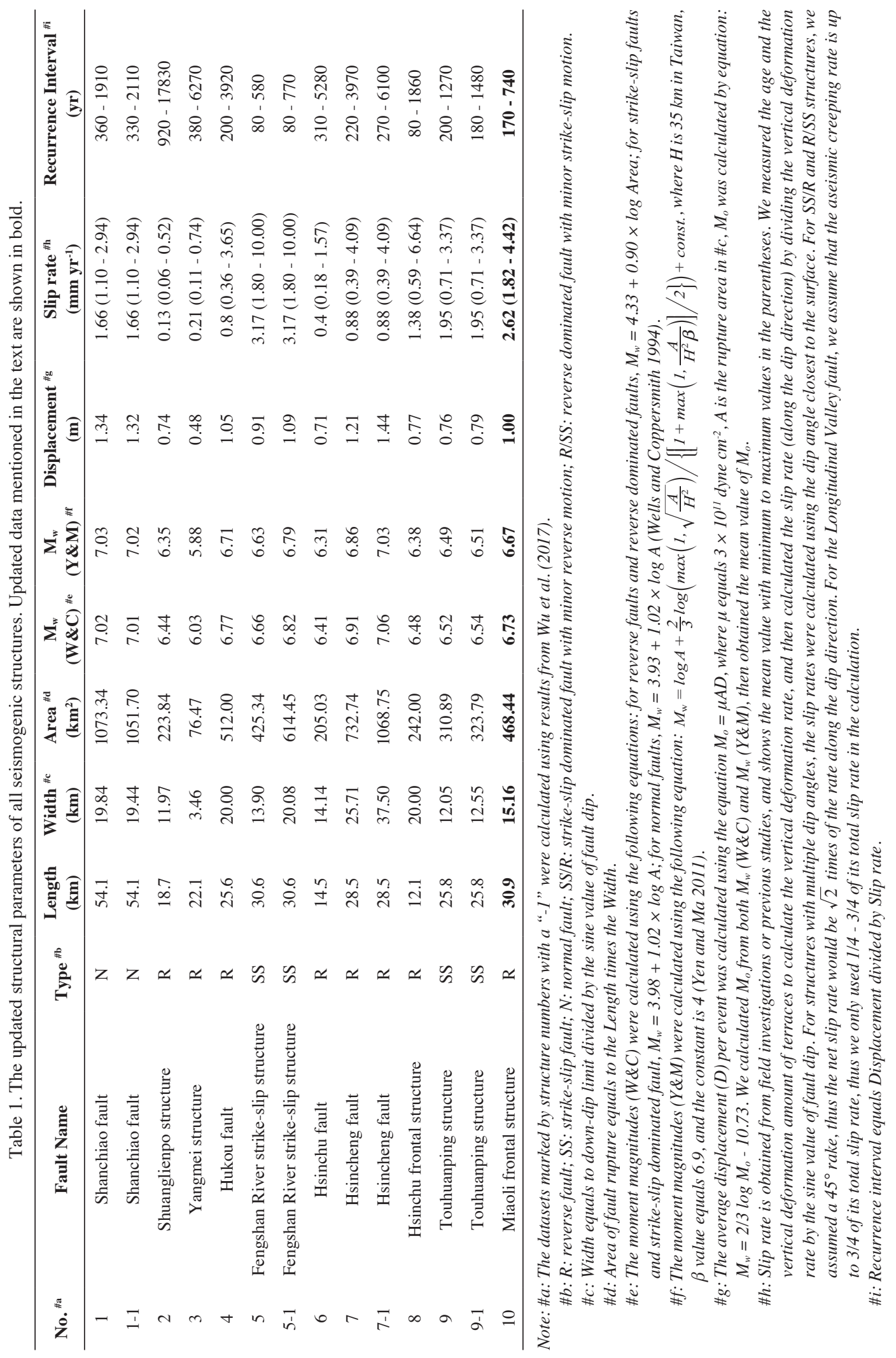




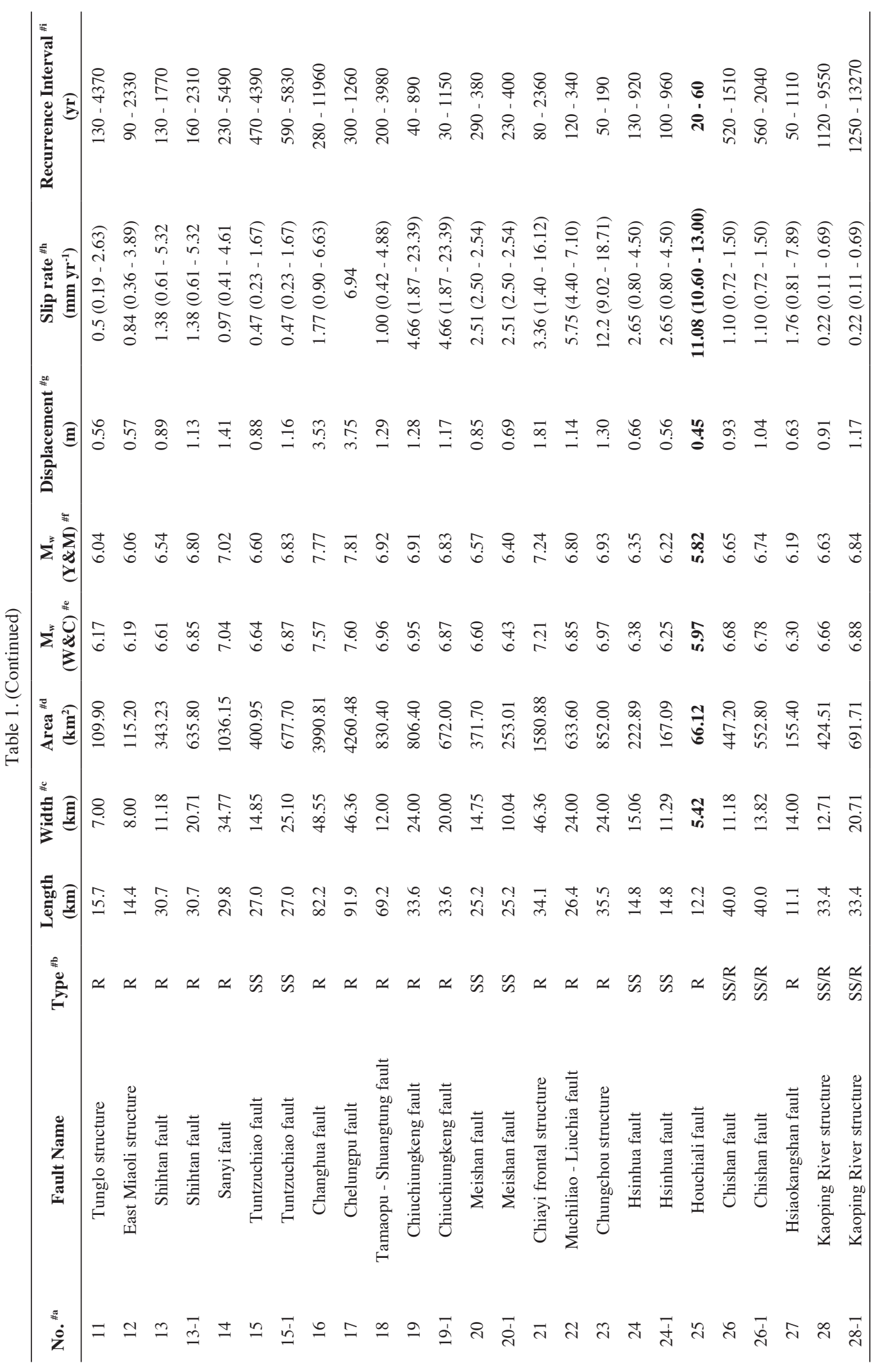




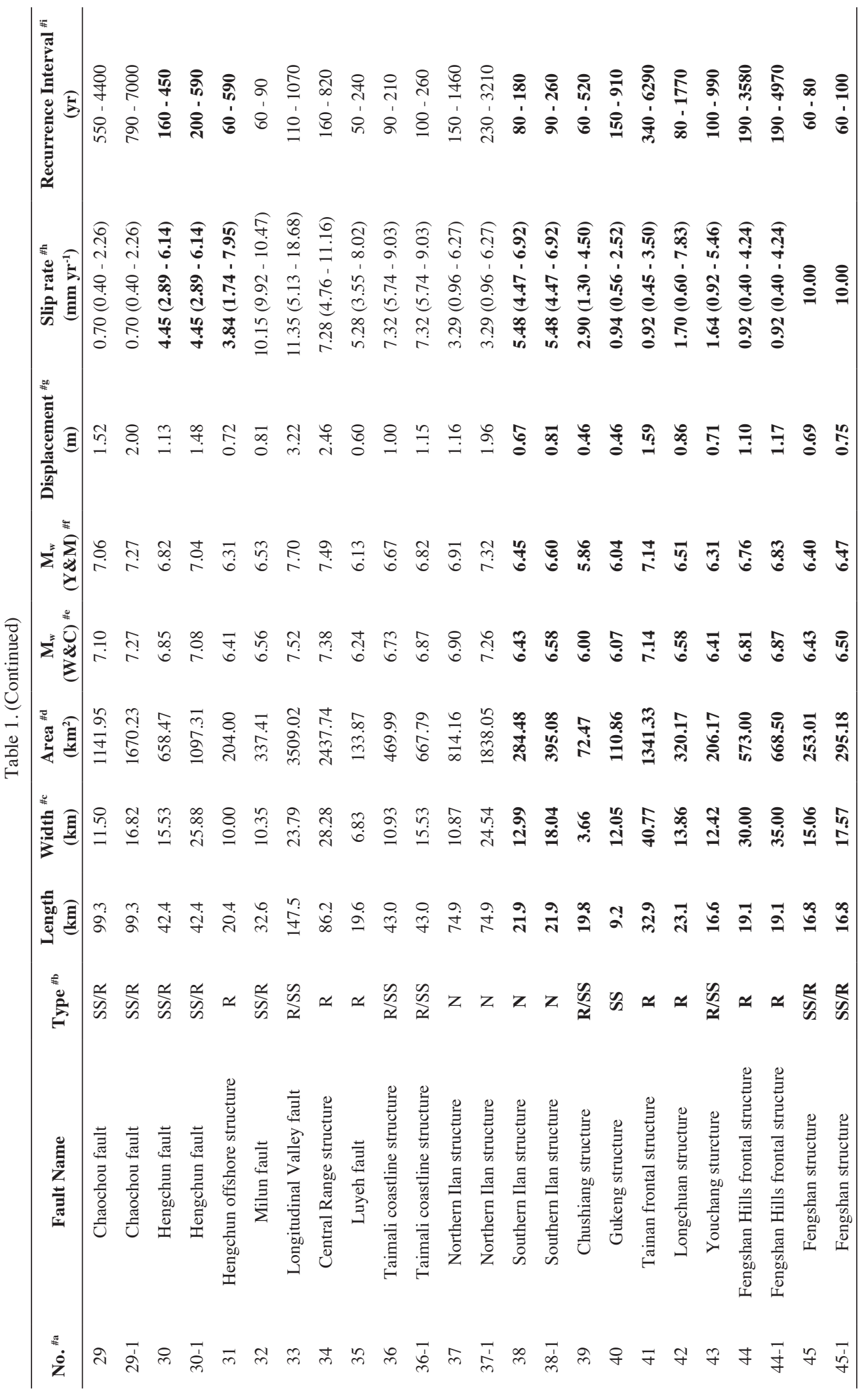


limited. For the seven new structures, only two of them (\#39 and \#45) have published long-term slip rates. Therefore, we have utilized the geomorphic method described in Shyu et al. (2016) to estimate reasonable long-term slip rates for the other five structures. In this method, we first determined the amount of structural deformation using the topographic features of the structures, usually scarps that cut across young fluvial surfaces. Ages of the deformed surfaces were then estimated using the soil categorization described in detail in Shyu et al. (2016). Finally, the long-term slip rates can be calculated using the amount of total deformation and age of the deformed surface. The following are the general information and parameters of these new structures:

39. The Chushiang structure in central Taiwan is a primarily reverse fault with minor right-lateral component. This structure is likely originated as a secondary fault that branched out from the Chelungpu fault (\#17) during the development of the central western Taiwan fold-andthrust belt (Lin et al. 2000). This structure connects the Chelungpu fault (\#17) and the Tamaopu-Shuangtung fault (\#18), thus it may be a transfer structure in the fold-and-thrust belt (Simoes et al. 2007). Using previously published information and structural model of this structure (e.g., Lin et al. 2000, 2019; Chen et al. 2004a), we propose that the structure is $19.8 \mathrm{~km}$ in length, dips at $55^{\circ}$, and extends to a depth of $3.0 \mathrm{~km}$. Based on geomorphic and geochronologic analyses results of Simoes et al. (2007), the long-tern slip rate of this structure is $2.9 \pm 1.6 \mathrm{~mm} \mathrm{yr}^{-1}$.

40. The Gukeng structure is a left-lateral fault in central Taiwan. Using previously published information (e.g., Chen et al. 2004b; Liu et al. 2004; Cheng et al. 2007), we propose that the length of this structure is $9.2 \mathrm{~km}$, and the structure dips at $85^{\circ}$ and extends to a depth of $12.0 \mathrm{~km}$. The structure appears to have offset the mountain front structure and the mountain front itself of the area (Liu et al. 2004), thus must be younger than the deposition age of the bedrocks of the mountain area. Based on the age data of Chi and Huang (1981) of the bedrocks, we obtained a long-term slip rate of this structure at $0.56-2.52 \mathrm{~mm} \mathrm{yr}^{-1}$.

41. The Tainan frontal structure is a blind fault beneath the coastal plain of the Tainan area in southwestern Taiwan. It was the southern part of the Chiayi frontal structure in the original database, but we separated this structure from the Chiayi frontal structure in the new database based on the differences in surface topography in the hanging-wall areas of these two structures. Based on the new mapping, the length of this structure is $32.9 \mathrm{~km}$. With a listric geometry, it dips at $30^{\circ}$ from 0 to $3 \mathrm{~km}$ deep, and at $15^{\circ}$ from 3 to $12.0 \mathrm{~km}$ deep. We estimated its slip rate at $0.45-3.5 \mathrm{~mm} \mathrm{yr}^{-1}$.

42. The Longchuan structure is located in the hilly area in southwestern Taiwan. We have added this structure based on previously published information (e.g., Cheng et al. 2007; Lin 2013). It is a reverse fault with a length of $23.1 \mathrm{~km}$. The depth of the structure is $12.0 \mathrm{~km}$, and the structure dips at $60^{\circ}$. Its slip rate is estimated at 0.6 $-7.83 \mathrm{~mm} \mathrm{yr}^{-1}$.

43. The Youchang structure is proposed in Cheng et al. (2007), and is located in the coastal area of southwestern Taiwan. It is a reverse dominated fault with minor right-lateral motion, and has a length of $16.6 \mathrm{~km}$. The structure dips at $75^{\circ}$ and extends to a depth of $12.0 \mathrm{~km}$. We calculated its slip rate at $0.92-5.46 \mathrm{~mm} \mathrm{yr}^{-1}$.

44. The Fengshan Hills frontal structure is located south of the Youchang structure in southwestern Taiwan, and is mapped as the structure that produced the uplift of the Fengshan Hills. It is a reverse fault and has a length of $19.1 \mathrm{~km}$. It dips at $30^{\circ}$ to a depth of $15.0 \mathrm{~km}$, and has an estimated slip rate of $0.4-4.24 \mathrm{~mm} \mathrm{yr}^{-1}$.

45. The Fengshan structure is located east of, and sub-parallel to the Fengshan Hills frontal structure. This structure is proposed in Deffontaines et al. (1997), and is a leftlateral dominated fault with minor reverse motion. Its length is $16.8 \mathrm{~km}$, dip is $85^{\circ}$, and it extends to a depth of $15.0 \mathrm{~km}$. Based on the GPS data of Ching et al. (2007), the slip rate of this structure is about $10 \mathrm{~mm} \mathrm{yr}^{-1}$.

Similar to the original database, we have also constructed three-dimensional subsurface models for the newly added structures (Fig. 2). These models enable us to check for geometrical conflicts, and to visualize the subsurface geometry of the structures. Some of the strike-slip dominant faults, such as the Gukeng structure (Fig. 2a) and Fengshan structure (Fig. 2c) appear to be tear faults that may cut through the surrounding reverse faults in the 3-D subsurface models. The detailed datasets of the 3-D seismogenic structural model for all structures, including these newly added ones, are included in a supplementary file of this paper.

\section{UPDATED PARAMETERS OF INDIVIDUAL STRUCTURES}

Based on results from new studies and our own field investigations, we have updated the structural parameters of four structures in the original database, as described below: 10. The geomorphic and structural features of the Miaoli frontal structure were analyzed in detail by Yuan (2018). Based on his mapping and structural reconstructions, we updated the length of this structure to be $30.9 \mathrm{~km}$, with a dip of $28^{\circ}$ to a depth of $7.0 \mathrm{~km}$. The long-term slip rate of this structure was originally estimated using a hypothetical age of the lateritic soil of the area (Shyu et al. 2016). With a new optically stimulated luminescence (OSL) age of a deformed terrace (Yuan 2018), we have calculated and updated the slip rate of the Miaoli frontal structure to be $1.82-4.42 \mathrm{~mm} \mathrm{yr}^{-1}$.

25. We have updated the structural parameters of the 
(a)

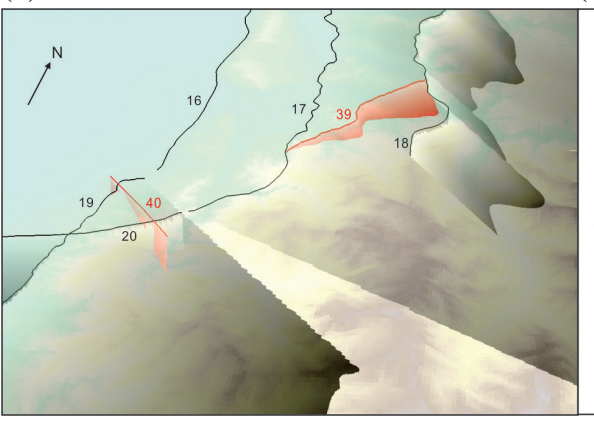

(b)

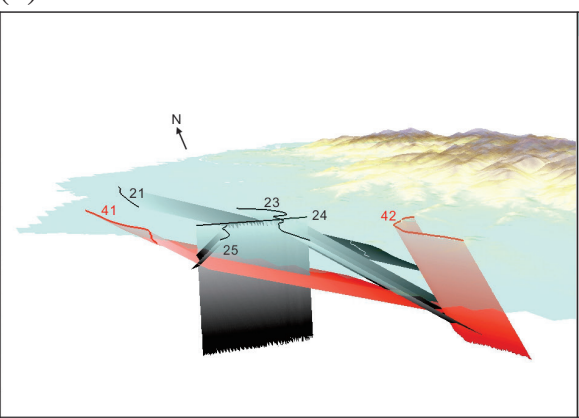

(c)

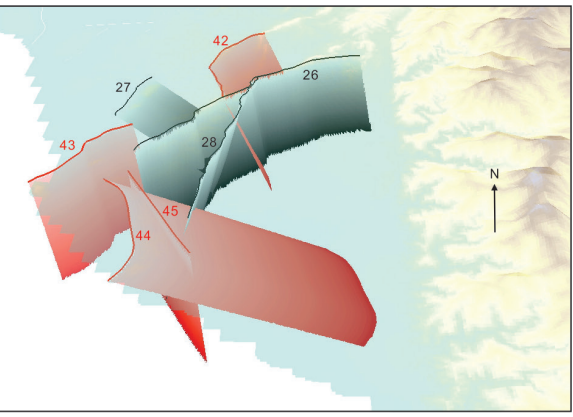

Fig. 2. Figures showing three-dimensional structural geometries below the surface of the seven newly added structures (shown as red polygons). The structural geometries are constrained mostly by information obtained from previously published literature. Numbers correspond to the structure number in Fig. 1 and Table 1. The background is the topography of Taiwan in (a) central Taiwan area, (b) Tainan area, and (c) Kaohsiung and Pingtung area.

Houchiali fault based on recently published information in Le Béon et al. (2019). Based on analyses of subsurface data and geodetic observations, Le Béon et al. (2019) reconstructed the subsurface structural geometry of the fault as a back thrust originated from the detachment at $3.8 \pm 0.4 \mathrm{~km}$ deep. With a calculated Holocene shortening rate across the fault, they have also constrained the long-term slip rate of the Houchiali fault as $11.8 \pm 1.2 \mathrm{~mm} \mathrm{yr}^{-1}$ (Le Béon et al. 2019).

30. We have collected uplifted coral samples from the hanging-wall block of the Hengchun fault in our field investigations. One of the samples was collected from a marine terrace 13 - $16 \mathrm{~m}$ above mean sea level, and has a U-Th age of $6416 \pm 39$ years BP. Based on this sample and the records of Holocene sea-level changes (Chen 1993), we have calculated and updated the long-term slip rate of the Hengchun fault to be $2.85-6.14 \mathrm{~mm} \mathrm{yr}^{-1}$.

31. Similarly, we have collected uplifted coral samples from the hanging-wall of the Hengchun offshore structure. One of the samples was collected at an elevation of 7.5 - $8 \mathrm{~m}$ above mean sea level, and has a U-Th age of 6649 \pm 31 years BP. With similar constraints as above, we have calculated and updated the long-term slip rate of this structure to be $1.74-7.95 \mathrm{~mm} \mathrm{yr}^{-1}$.

\section{SYSTEMATIC UPDATES OF THE PARAMETERS IN THE DATABASE}

Several systematic changes and updates of the structural parameters in the TEM seismogenic structure database were performed after the publication of its first version. For example, with more detailed mapping using a higher resolution digital elevation model (DEM), we have updated the structural lengths of most structures. A column of last earthquake event of each structure was added to the parameter table based on available historical documentations or geological constraints. Due to the limited number of well con- strained historical earthquake documents, many of the data in this column have enormous uncertainties. Nonetheless, such information would provide a basis for the calculation of time-dependent seismic hazard assessments.

Most of the structural parameters in the original database do not have uncertainties, which is not reasonable. Therefore, we have attempted to include uncertainties for all parameters in the updated database. For example, we have considered and added potential uncertainties of structural depth and dipping angle of each structure, and included these in the updated parameter table.

The rupture depth that was used to constrain rupture width of each seismogenic structure in the original database was largely calculated using the geothermal gradient data of Taiwan proposed by Liu et al. (2015). Alternatively, the rupture depth of structures may also be constrained using several other methods proposed in the literature. Wu et al. (2017), for example, calculated the distribution patterns of earthquake moment at different depths in Taiwan's crust, and used different distribution percentages to determine the onset and cutoff depths of seismicity, such as $1 \%$ (D1), 5\% (D5), 10\% (D10), 90\% (D90), 95\% (D95), and 99\% (D99). The thicknesses of D10-90, D5-95, and D1-99 can respectively indicate the minimum, mean and maximum rupture depths of crustal structures. Since this result provides another constraint for structures that extend to the brittle-ductile transition than the geothermal gradient data, we calculated another set of parameters of those structures, and listed the new set of parameters together with the original set. In the updated parameter table, the new set of data was marked by structure numbers with a "-1" (Table 1).

In the original database, the moment magnitudes $\left(\mathrm{M}_{\mathrm{w}}\right)$ of earthquakes likely produced by the seismogenic structures were calculated using the published regression result from Wells and Coppersmith (1994). Whereas this result has been widely applied in many studies, many alternative models are available (e.g., Wesnousky 2008; Blaser et al. 
2010; Stirling et al. 2013). A local regression relationship for crustal structures was also published by Yen and Ma (2011). Therefore, we have calculated another set of moment magnitude of each structure using the Yen and Ma (2011) model. Although there is no significant difference between the results using the two different models, these results enabled us to obtain and calculate the maximum, minimum and mean value of $\mathrm{M}_{\mathrm{w}}$, seismic moment, and the average slip per earthquake event.

With all the updated structural parameters that include better considerations of uncertainties, we were able to calculate and update the average recurrence interval of each seismogenic structures (Table 1 and Fig. 3). A complete structural parameter table and the ArcGIS shapefiles of all structures that reflect all of the updates are included in the supplementary files of this paper.

\section{SUMMARY}

As part of the ongoing efforts of the Taiwan Earthquake Model project, we have updated the original on-land seismogenic structure database of Taiwan (Shyu et al. 2016) based on the integration of results from new and past pub- lications and from our own field investigations. Seven new structures were identified and added into the new version of the database. Parameters of four existing structures, including the Maoli frontal structure, the Houchiali fault, the Hengchun fault, and the Hengchun offshore structure were updated with new results. We have also systematically updated the parameters of all structures with more detailed mapping, alternative calculation methods, and better consideration of parameter uncertainties. As we mentioned in the first version of the database, we anticipate this database will continue to improve and be updated as more new data become available, and this new version would provide more comprehensive information for future seismic hazard assessment studies in Taiwan.

Acknowledgements We are grateful for the valuable comments from and discussion with C.-H. Chan, C.-T. Cheng, S.-N. Cheng, K.-E. Ching, C.-T. Lee, Y.-R. Lee, Y.-T. Lee, K.-F. Ma, R.-J. Rau, Y.-R. Wang, K.-L. Wen and Y.-T. Yen. The comments and suggestions from two anonymous reviewers significantly improved this manuscript. This research is supported by the Ministry of Science and Technology (MOST) of Taiwan (Project 105-2119-M-006-016, (a)

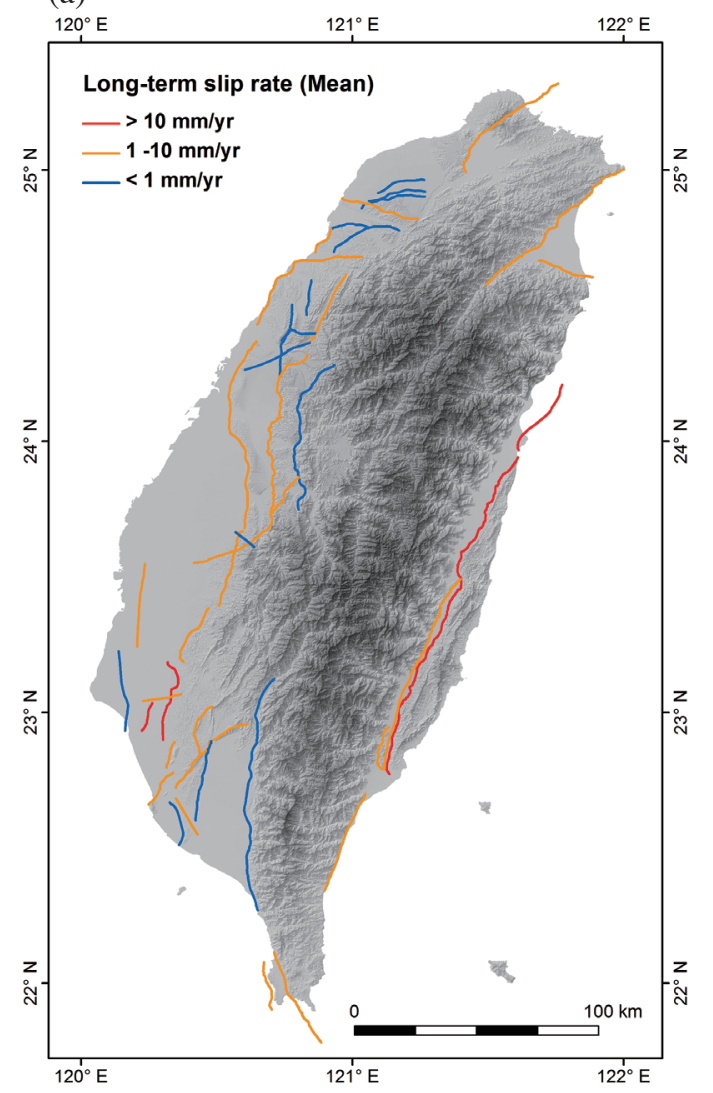

(b)

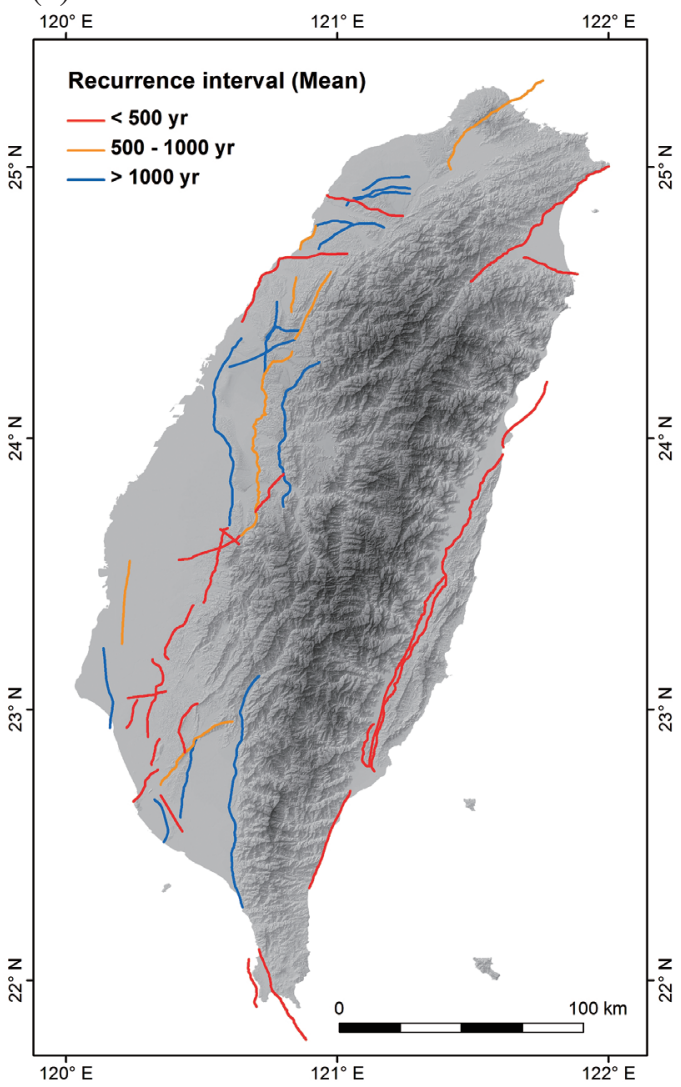

Fig. 3. Maps showing a summary of (a) mean long-term slip rates and (b) mean average recurrence intervals of the 45 seismogenic structures in Taiwan. Most of the structures have long-term slip rates between 1 and $10 \mathrm{~mm} \mathrm{yr}^{-1}$, and more than half of the structures have earthquake recurrence intervals less than 500 years, posing significant earthquake hazard potentials for the island. 
106-2119-M-006-012, 107-2119-M-006-011, 108-2119-M006-004, and 109-2124-M-002-006 as the TEM project, and 108-2116-M-002-016-MY2 to J.B.H.S.).

\section{REFERENCES}

Blaser, L., F. Krüger, M. Ohrnberger, and F. Scherbaum, 2010: Scaling relations of earthquake source parameter estimates with special focus on subduction environment. Bull. Seismol. Soc. Am., 100, 2914-2926, doi: 10.1785/0120100111. [Link]

Central Geological Survey, 1999: Report of the Geological Survey of the 1999 Chi-Chi Earthquake, Central Geological Survey, Taipei, Taiwan, 314 pp. (in Chinese)

Chen, H.-W., M.-M. Chen, and T.-S. Shih, 2004a: Nantou, Geological Map of Taiwan Scale 1:50,000, Sheet 31, Central Geological Survey, MOEA, Taipei, Taiwan.

Chen, W.-S., C.-C. Yang, H.-C. Yang, L.-C. Wu, C.-W. Lin, H.-C. Chang, R.-C. Shih, W.-H. Lin, Y.-H. Lee, T.-S. Shih, and S.-D. Lu, 2004b: Tectono-geomorphologic studies in the Chiayi-Tainan region in southwestern Taiwan and its implications for active structure. Bull. Cent. Geol. Surv., 17, 53-78. (in Chinese with English abstract)

Chen, Y.-G. 1993: Sea-level change and neotectonics in southern part of Taiwan region since Late Pleistocene. Ph.D. Thesis, National Taiwan University, Taipei, Taiwan, 158 pp. (in Chinese)

Cheng, C.-T., S.-J. Chiou, C.-T. Lee, and Y.-B. Tsai, 2007: Study on probabilistic seismic hazard maps of Taiwan after Chi-Chi earthquake. J. GeoEngineering , 2, 19-28, doi: 10.6310/jog.2007.2(1).3. [Link]

Cheng, C.-T., C.-T. Lee, P.-S. Lin, B.-S. Lin, Y.-B. Tsai, and S.-J. Chiou, 2010: Probabilistic earthquake hazard in metropolitan Taipei and its surrounding regions. Terr. Atmos. Ocean. Sci., 21, 429-446, doi: 10.3319/ TAO.2009.11.11.01(TH). [Link]

Chi, W.-R. and H.-M. Huang, 1981: Nannobiostratigraphy and paleoenvironments of the late Neogene sediments and their tectonics implications in the Miaoli area, Taiwan. Petroleum Geology of Taiwan, 18, 111-129.

Ching, K.-E., R.-J. Rau, J.-C. Lee, and J.-C. Hu, 2007: Contemporary deformation of tectonic escape in SW Taiwan from GPS observations, 1995-2005. Earth Planet. Sci. Lett., 262, 601-619, doi: 10.1016/j. eps1.2007.08.017. [Link]

Deffontaines, B., O. Lacombe, J. Angelier, H. T. Chu, F. Mouthereau, C. T. Lee, J. Deramond, J. F. Lee, M. S. Yu, and P. M. Liew, 1997: Quaternary transfer faulting in the Taiwan Foothills: Evidence from a multisource approach. Tectonophysics, 274, 61-82, doi: 10.1016/ s0040-1951(96)00298-3. [Link]

Le Béon, M., O. Marc, J. Suppe, M.-H. Huang, S.-T. Huang, and W.-S. Chen, 2019: Structure and deformation his- tory of the rapidly growing Tainan anticline at the deformation front of the Taiwan mountain belt. Tectonics, 38, 3311-3334, doi: 10.1029/2019tc005510. [Link]

Lin, C.-W., 2013: Qishan, Geological Map of Taiwan Scale 1:50,000, Sheet 56, Qishan, Central Geological Survey, MOEA, Taipei, Taiwan.

Lin, C.-W., S.-T. Lu, W.-J. Huang, T.-S. Shih, and H.-C. Chang, 2000: The Chi-Chi earthquake fault and structural analysis of the area south of Choshuihsi, central Taiwan. Spec. Publ. Cent. Geol. Surv., 12, 89-111. (in Chinese with English abstract)

Lin, C.-W., P.-S. Chou, and Y.-J. Chang, 2019: Structural features and their significance of the Cholan Formation in Choshui River area, central Taiwan. Spec. Publ. Cent. Geol. Surv., 34, 1-23. (in Chinese with English abstract)

Liu, C.-M., S.-R. Song, and C.-H. Kuo, 2015: Silica geothermometry applications in the Taiwan orogenic belt. Terr. Atmos. Ocean. Sci., 26, 387-396, doi: 10.3319/ TAO.2015.02.09.01(TT). [Link]

Liu, H.-C., J.-F. Lee, and C.-C. Chi, 2004: Yunlin, Geological Map of Taiwan Scale 1:50,000, Sheet 38, Central Geological Survey, MOEA, Taipei, Taiwan.

Shyu, J. B. H., K. Sieh, Y.-G. Chen, and C.-S. Liu, 2005: Neotectonic architecture of Taiwan and its implications for future large earthquakes. J. Geophys. Res., 110, B08402, doi: 10.1029/2004JB003251. [Link]

Shyu, J. B. H., Y.-R. Chuang, Y.-L. Chen, Y.-R. Lee, and C.-T. Cheng, 2016: A new on-land seismogenic structure source database from the Taiwan Earthquake Model (TEM) project for seismic hazard analysis of Taiwan. Terr. Atmos. Ocean. Sci., 27, 311-323, doi: 10.3319/TAO.2015.11.27.02(TEM). [Link]

Simoes, M., J. P. Avouac, and Y.-G. Chen, 2007: Slip rates on the Chelungpu and Chushiang thrust faults inferred from a deformed strath terrace along the Dungpuna river, west central Taiwan. J. Geophys. Res., 112, B03S10, doi: 10.1029/2005JB004200. [Link]

Stirling, M., T. Goded, K. Berryman, and N. Litchfield, 2013: Selection of earthquake scaling relationships for seismic-hazard analysis. Bull. Seismol. Soc. Am., 103, 2993-3011, doi: 10.1785/0120130052. [Link]

Wang, Y.-J., C.-H. Chan, Y.-T. Lee, K.-F. Ma, J. B. H. Shyu, R.-J. Rau, and C.-T. Cheng, 2016: Probabilistic seismic hazard assessment for Taiwan. Terr. Atmos. Ocean. Sci., 27, 325-340, doi: 10.3319/ TAO.2016.05.03.01(TEM). [Link]

Wells, D. L. and K. J. Coppersmith, 1994: New empirical relationships among magnitude, rupture length, rupture width, rupture area, and surface displacement. Bull. Seismol. Soc. Am., 84, 974-1002.

Wesnousky, S. G., 2008: Displacement and geometrical characteristics of earthquake surface ruptures: Issues and implications for seismic-hazard analysis and the 
process of earthquake rupture. Bull. Seismol.Soc. Am., 98, 1609-1632, doi: 10.1785/0120070111. [Link]

Wu, W.-N., Y.-T. Yen, Y.-J. Hsu, Y.-M. Wu, J.-Y. Lin, and S.-K. Hsu, 2017: Spatial variation of seismogenic depths of crustal earthquakes in the Taiwan region: Implications for seismic hazard assessment. Tectonophysics, 708, 81-95, doi: 10.1016/j.tecto.2017.04.028. [Link]

Yen, Y.-T. and K.-F. Ma, 2011: Source-scaling relationship for M 4.6-8.9 earthquakes, specifically for earthquakes in the collision zone of Taiwan. Bull. Seismol. Soc. Am., 101, 464-481, doi: 10.1785/0120100046. [Link]

Yuan, Y.-W., 2018: Active deformation of coastal and fluvial terraces by the blind Miaoli frontal structure in the Miaoli coastal area, western Taiwan. Master Thesis, National Taiwan University, Taipei, Taiwan, 115 pp. (in Chinese with English abstract) 